\title{
MÚSICA POPULAR: FONTES E ACERVOS
}

JOSÉ GERALDO VINCI DE MORAES 
Mário de Andrade abre pequeno texto de 1936 afirmando que "O estudo científico da música popular brasileira ainda está por se fazer" Com o objetivo evidente de ultrapassar esses limites, parte expressiva da obra é composta de indicações comentadas de instituições públicas, discografia, bibliografia e documentação musical e poética que poderiam justamente colaborar no "estudo científico" da "música popular nacional". Por essa razão, Oneyda Alvarenga afirma que o texto tem "caráter doutrinário e informativo"

Para o musicólogo modernista, como se sabe, as origens e evolução da "Música Popular Brasileira", de que se ocupariam os "estudos científicos", deveriam ser procuradas e compreendidas no universo das tradições folclóricas. Nas manifestações dos gêneros da música urbana que despontavam no início do século xx, acompanhando o ritmo acelerado de crescimento das cidades e culturas citadinas, ele considerava que o pesquisador deveria discernir "no folclore urbano" o que era "virtualmente autóctone, o que é tradicionalmente nacional"', como os choros e modinhas. Chegou até a reconhecer, em alguns compositores que viviam no mundo do entretenimento e dos meios de comunicação, certa relevância cultural e musical, como "Donga, Sinhô e Noel Rosa, [...] as figuras mais interessantes do samba impresso" ${ }^{2} \mathrm{Po}-$ rém, era fundamental diferenciar a "boa música popular", com características "artísticas e nacionais" fundadas no folclore, da "popularesca", geralmente sua contrafação, divulgada pelos meios de comunicação.

Pouco antes, em 1933, o jornalista carioca Vagalume publicou o livro Na roda do samba, relatando suas experiências em universo distinto: as rodas de samba urbano, da boêmia e do carnaval carioca. Logo no início da obra ele ressalta que se trata de um "modestíssimo trabalho que, longe de ser uma obra literária, é apenas um punhado de crônicas" aliás, impressão confirmada por Jota Efegể nas apresentações da primeira (1933) e segunda (1978) edições. Contudo, para além da "simples crônica", os jornalistas também deixaram transparecer duas outras dimensões existentes no trabalho: certa aspiração "científica" e a relevância cultural de seu objeto. Vagalume diz que o livro também é "o resultado das minhas investigações sobre o samba, que, já está ficando por cima da carne seca, como se diz na gíria da gente dos morros [...]" e que "nas minhas investigações que o leitor amigo (ou inimigo) vai ler, poderei não agradar no estilo, mas, uma coisa eu garanto - o que falta em flores de retórica, sobra em informações bebidas em fontes autorizadas e insuspeitas" " Jota Efegê de novo concor- 
da com ele, pois afirma que "numa ronda de arqueólogo, misto de repórter e de boêmio, ele gira com ela, ouvindo a sua gente, opinando sobre sua produção [...]. Como um bom historiador, 'começa do princípio', e dá-nos nas primeiras páginas de seu livro a origem do samba [...]" ${ }^{5}$ Afirmações como essas levam o leitor a crer que a obra ultrapassa a simples crônica e o registro memorialístico, para operar no universo da reconstrução e avaliação etnográfica (ou arqueológica, como quer Efegê) e historiográfica. Apesar de o objetivo central do autor ser de outra ordem, parece haver a preocupação, ainda que submersa, com a compreensão desse novo fenômeno cultural e social que era a "moderna" música urbana.

Desse modo, surgem aparentes convergências entre Mário de Andrade e Vagalume, centradas na "preocupação científica" com esse objeto. Desprezando a exagerada ambição cientificista, é possível perceber que há nos dois autores preocupação evidente com a recuperação, preservação e a compreensão sistemática da música popular. No entanto, elas se desvanecem rapidamente: a distinção clara entre os objetos a serem estudados e preservados - o folclore para o musicólogo e a canção urbana para o jornalista - revela as diferentes preocupações e projetos de cada um. Essa oposição, exposta nos anos 30, permaneceu viva marcando profundamente a memória, os acervos, as políticas de preservação e os estudos sobre a música popular.

A perspectiva do modernista e suas temáticas tornaram-se hegemônicas e formaram sólida corrente composta de folcloristas, musicólogos e etnomusicólogos, geralmente sediados nas universidades, escolas, academias, conservatórios e nas instituições do Estado. Em contrapartida, o universo cultural e musical foco das narrações de Vagalume muito raramente fez parte das preocupações dessas instituições - quando não foi combatido por elas! —, mantendo-se limitado à crônica jornalística, aos colecionadores, diletantes, relicários e amadores, criando outro tipo de compreensão e produção do conhecimento em torno da música popular.

Marginalizada pela elite intelectual e desprezada pelas instituições de educação e pesquisa, a memória da música popular urbana ficou praticamente esquecida, permanecendo sob suposta "responsabilidade" das iniciativas dos interessados pelo tema ou envolvidos profissionalmente com ele. Essa prática iniciada na geração de Vagalume permaneceu viva (com Jota Efegê, Almirante, Lúcio Rangel, entre outros), solidificou-se 
e desenvolveu-se nas décadas seguintes, formando destacado conjunto de acervos e análises da música popular. Esse núcleo durante muito tempo foi praticamente o único a contribuir para a compreensão da música urbana. Sem eles, provavelmente a reconstrução de parte da cultura do país pela música seria muito mais complicada ou quase impossível, ainda que a maior parte dessa produção tenha sido assinalada pelo tom biográfico, impressionista e apologético, fundado em paradigma historiográfico tradicional.

Essas restrições e embates culturais e políticos determinaram as limitações das fontes e da disponibilização dos acervos, impondo uma série interminável de dificuldades para aqueles que pretendiam (ou ainda pretendem) estudar a música popular urbana: os arquivos e discotecas públicas são raros e sobrevivem com muitas dificuldades, impedindo, na maioria das vezes, o acesso às fontes; são poucos os arquivos e bibliotecas organizadas de partituras, folhas avulsas, compilações sistemáticas e catalogações; as indústrias fonográfica e radiofônica não formaram seus próprios acervos de discos e CD's de gravações de discos e programas radiofônicos se perderam ou estão nas māos de colecionadores; não há quantificação e sistematização da produção fono- gráfica e muito menos da difusão de canções em espetáculos, nos meios eletrônicos etc. Carlos Sandroni, em seu mais recente trabalho, levanta essas antigas dificuldades, mas avalia que, felizmente, o esforço individual de aficionados e colecionadores preservou, nas suas coleções de discos, fragmentos do acervo musical do país.?

Todavia, essa é uma situação paradoxal que amplifica as dificuldades originais. A atitude desses colecionadores é notável e merece reconhecimento e agradecimento público, mas ao mesmo tempo recoloca e aprofunda o problema em diversos níveis. Em primeiro lugar, ela revela verdadeira privatização da memória (ainda que não propositada), uma vez que obras e arquivos - partes importantes de nossa história cultural coletiva - estão concentrados em mãos dos colecionadores e revelam gosto, universo cultural e seleção muito particulares. $\mathrm{O}$ desdobramento imediato dessa situação é a disponibilização e abertura dos acervos apenas aos "iniciados", determinando dupla seleção das fontes e pesquisadores. Além disso, nem sempre os acervos são bem preservados e organizados, pois geralmente os proprietários têm dificuldades em mantê-los, já que não recebem nenhum tipo de subsídio. Por fim, o acesso ao público nem sempre é fácil e depende da boa vontade e tempo dos cole- 
cionadores (que, felizmente, de modo geral são bastante acessíveis). ${ }^{8}$

Esse quadro contraditório e angustiante se perpetua, uma vez que a preocupação das instituições públicas com esse tipo de acervo permanece muito rarefeita. Mesmo quando surge a iniciativa política nessa direção, ela continua gerando desconfianças. Os tradicionais colecionadores, por exemplo, preocupados com o futuro, preservação e unidade de seus acervos, não encontram interesse pela compra completa de suas coleções e receiam pela fragmentação ou diluição delas. Por outro lado, a compra integral das coleções não significa sua preservação, pois geralmente as instituiçōes têm dificuldade administrativa e de continuidade política para organizá-las e mantê-las (como ocorre ainda hoje de modo sistemático com os acervos existentes no mis do Rio de Janeiro e de São Paulo). Isso significa que muitas vezes o acesso às fontes para consulta e pesquisa se torna mais complicado do que nos arquivos particulares. Já nos antigos acervos públicos, os problemas podem ser ainda mais graves, colocando em risco as coleções, como é o caso da Discoteca Oneyda Alvarenga (originária da Discoteca Pública criada por Mário de Andrade), que, após circular por diversos espaços da administração munici- pal de São Paulo, se encontra no Centro Cultural de São Paulo em permanente condição de organização e manutenção, dificultando o acesso. ${ }^{9}$

Mais recentemente essa situação começou a sofrer relativa mudança com a criação de políticas mais sólidas e claras de produção de acervos e pesquisas. O Programa Petrobrás de Música, que visa a criar linha de patrocínio para a formação de acervos - além de outras políticas de apoio à preservação da memória musical -, e a ação do Instituto Moreira Salles, que criou junto com a empresa estatal o Centro de Referência de Música Brasileira, são exemplos bem sucedidos nesta direção. Inicialmente o IMs comprou, organizou e já disponibilizou ao público o acervo de Humberto Franceschi e está organizando o do historiador José Ramos Tinhorão. A coleção de Humberto Franceschi pode ser consultada na sede do СРR мв no Rio de Janeiro e está disponível para audição e consulta em endereço na internet (www.ims.com.br). Destino semelhante será dado ao acervo e biblioteca de José R. Tinhorão, sediados em São Paulo.

Já o Programa Petrobrás de Música pretende criar uma política permanente de reflexão e preservação da música brasileira. Alguns de seus princípios gerais apontam tanto para a criação de acervos vivos da memória musical do país, como para o diálogo permanente en- 
tre passado-presente. ${ }^{10}$ Assim, pretende apoiar a revitalização, preservação e disponibilização de acervos públicos e privados (numa perspectiva "retrospectiva") e, ao mesmo tempo, o registro por meio de edição e gravação de manifestações musicais que não têm espaço no mercado (numa ação prospectiva). Essa dupla ação tem em vista a produção da pesquisa e também seu retorno à sociedade, para escapar do embalsamento da cultura (fato que geralmente ocorre com os acervos particulares).

É bom que se registre também que antes dessas iniciativas já havia importantes núcleos que sobreviveram bem à falta de apoio e às dificuldades institucionais de toda ordem. O setor de música da Biblioteca Nacional do Rio de Janeiro e a Fonoteca da Fundação Joaquim Nabuco, criada em 1980 $0^{11}$, são bons exemplos entre as instituições públicas. No setor privado, a Revivendo e a Collector's há anos disponibilizam de maneira comercial e muito eficiente seus arquivos. As duas empresas comerciais surgiram nos anos 80 baseadas em acervos de colecionadores particulares (respectivamente Leon Barg e José Maria Manzo), mas também com o objetivo genérico "de resgatar e preservar a memória da música popular brasileira"12.

A continuar nesse ritmo de mudanças e ações envol- vendo arquivos, fontes e documentação, o estímulo à produção de pesquisas em torno da música popular tenderá a acelerar, desfazendo o hiato original e aproximando definitivamente Mário de Andrade e Vagalume. No circuito dos historiadores de ofício, por exemplo, as pesquisas de temas relacionados direta ou indiretamente à música e à canção popular urbana têm se multiplicado. Claro que as transformações teóricas das últimas décadas, as novas concepções de material documental e a prática renovada do historiador permitiram a incorporação de novas linguagens pela História, entre elas a música. Apesar dos evidentes avanços, as potencialidades que as relações entre História e música podem oferecer, para a construção do conhecimento histórico, ainda são campos pouco explorados e discutidos pela historiografia, especialmente os temas ligados à música popular. Provavelmente as ações relativas à preservação e disponibilização das fontes e acervos darão novo ânimo aos historiadores e demais pesquisadores, incentivando, sobretudo, novas temáticas, problematizações e interpretações. Porém, na verdade, a única certeza que resta desta trajetória iniciada no começo do século xx é o sentido / a condição realista - às vezes cruel! - que se revela no alerta do historiador francês Marc Bloch: os documentos não sur- 


\section{gem por "mágicas" e sua presença ou ausência em ar- quivos e bibliotecas dependem "de causas humanas" 13}

1 ANDRADE, Mário de. "A música e a cançāo populares no Brasill."In: Ensaios sobre a música brasileira. São Paulo: Martins, 1962, p. 163 e 167.

2 Idem. Pequena história da música. 9a ed. Sāo Paulo: Martins, 1980 p. 193.

3 Francisco Guimarāes (Vagalume. 1875 - RJ - 1946/47): mestiço, fiIho de família pobre, o apelido surgiu da coluna que escrevia no Jornal do Brasile n'A Tribuna sobre fatos policiais, a boêmia, o carnaval e música popular. João Ferreira Gomes (Jota Efegê. 1902 - RJ — 1987): no final dos anos 20 começou a fazer crônica carnavalesca em jornais e revistas, tornando-se um dos maiores cronistas da música popular do período.

4 GUIMARĀES, Francisco (Vagalume). Na roda do samba. $2^{\text {a }}$ ed. Rio de Janeiro: Funarte, p. 19-20. (MPB reedições)

5 Ibidem, p. 237.

6 Na década de 60, Edigar de Alencar já reclamava e alertava para essa situação ao indicar que "ao que parece, nunca houve por parte das gravadoras o propósito alto de colaborar na fixação de pormenores essenciais ao levantamento da história musical do Brasil" Nosso Sinhô do Samba. Rio de Janeiro: Civilização Brasileira, 1968, p. 172.

7 SANDRONI, Carlos. Feitiço decente: transformações do samba no Rio de Janeiro (1917-1933). Rio de Janeiro: Ed. ufrs/Zahar, 2001, p. 187.

8 Até muito recentemente a situação dos acervos particulares de
Ronoel Simões, Padre Jaime Diniz, Ary Vasconcelos, Miguel A de Azevedo (Nirez) e de Luiz Antonio de Almeida era bastante difícil e precária. Apesar da "boa vontade" de Nirez, ele afirma que teve que "restringir o acesso a apenas alguns estudantes porque não tenho recursos para manter um museu," (Carta Capital, p. 17. 17.10.2001). Aliás, o acervo do colecionador nordestino recentemente recebeu verba do Programa Petrobrás de Música, para manutenção, digitalização e disponibilização.

9 Ver MACHADO, Cacá. Acervos vivos, memória precária. Reportagem. Revista da oficina de informações, ano Iv, n. 38, p. 40-2, nov. de 2002. Atualmente o acervo está sendo digitalizado também com apoio do Programa da Petrobrás de Música.

10 In: www.petrobras.com.br/musica

11 Informações básicas podem ser encontradas no endereço www.fundaj.gov.br/isis/disco.html

12 A Collector's desde 1991 tem acordo com O MIS-RJ, apresentando também parte de seu acervo. Os acervos podem ser consultados nos endereços www.collectors.com.br e www.revivendomusicas.com.br

13 BLOCH, Marc. Introdução à História. $5^{a}$ ed. Sintra: Coleçāo Europa-América, s/d, p. 65-6.

José Geraldo Vinci de Moraes é professor do Departamento de História da FFLCH-USP 